\title{
Papers
}

\section{Age at retirement and long term survival of an industrial population: prospective cohort study}

\author{
Shan P Tsai, Judy K Wendt, Robin P Donnelly, Geert de Jong, Farah S Ahmed
}

\begin{abstract}
Objective To assess whether early retirement is associated with better survival.

Design Long term prospective cohort study.

Setting Petroleum and petrochemical industry, United States. Subjects Past employees of Shell Oil who retired at ages 55, 60, and 65 between 1 January 1973 and 31 December 2003.

Main outcome measure Hazard ratio of death adjusted for sex, year of entry to study, and socioeconomic status.

Results Subjects who retired early at 55 and who were still alive at 65 had a significantly higher mortality than those who retired at 65 (hazard ratio $1.37,95 \%$ confidence interval 1.09 to 1.73 ).

Mortality was also significantly higher for subjects in the first 10 years after retirement at 55 compared with those who continued working $(1.89,1.58$ to 2.27$)$. After adjustment, mortality was similar between those who retired at 60 and those who retired at 65 (1.06, 0.92 to 1.22). Mortality did not differ for the first five years after retirement at 60 compared with continuing work at 60 (1.04, 0.82 to 1.31$)$.

Conclusions Retiring early at 55 or 60 was not associated with better survival than retiring at 65 in a cohort of past employees of the petrochemical industry. Mortality was higher in employees who retired at 55 than in those who continued working.
\end{abstract}

\section{Introduction}

Few studies have evaluated the effect of early retirement on survival. ${ }^{1-4}$ A longitudinal evaluation of survival patterns requires a relatively long length of follow-up after retirement. In addition, data on age and health status at retirement are not readily available for the US general population. To date no consensus has been reached on the survival or mortality of people who retire early compared with those who retire later. ${ }^{4}$ Some researchers concluded that early retirement harms health, attributing this to illness before retirement or the change of life events associated with retirement. ${ }^{13}$ On the other hand, there is a widespread perception that early retirement is associated with longer life expectancy and that retiring later leads to early death. ${ }^{56}$ The possible health benefits of retirement, such as reduced role demand and a more relaxed lifestyle, have been postulated to improve longevity among people who retire early.?

We carried out a long term prospective cohort study of employees of the petrochemical industry in the United States who retired at 55,60 , and 65 to assess whether there is any survival advantage of early retirement.

\section{Subjects and methods}

Our study population consisted of all past employees of Shell Oil in the United States who retired at 55,60 , or 65 , and employees who were actively working at 55 or 60 , during a period of 31 years between 1 January 1973 and 31 December 2003. In the main analysis we compared the survival of employees who retired at $55(\mathrm{n}=839)$ and $60(\mathrm{n}=1929)$ and were still alive at 65 with those who retired at $65(\mathrm{n}=900)$. The average ages at the end of the study were 72,76 , and 80 , with, respectively, $10 \%, 20 \%$, and $52 \%$ over 80 . We followed up employees who retired at 55 or 60 from the time they reached 65 . We excluded the first 10 years of survival for those retiring at 55, and we determined time to death from age 65 , or the end of the study, whichever was earlier, yielding 21 years of follow-up and 173 deaths. We excluded the first five years of survival for those retiring at 60 , yielding 26 years of follow-up and 581 deaths.

To assess the health status of those who retired before the normal retirement age of 65 , we compared the mortality of those who retired at $55(\mathrm{n}=1439)$ or $60(\mathrm{n}=2116)$ with those who were still working at $55(\mathrm{n}=15543)$ or $60(\mathrm{n}=6783)$. If early retirement before 65 was taken by some workers because of failing health, mortality would be expected to be higher among early retirees than among those who did not retire at these ages. Overall, 137 employees who retired at 55 and 994 employees who continued working at 55 died by age 65 , whereas 98 employees who retired at 60 and 317 employees who continued working at 60 died by age 65 . We calculated the hazard ratio for the first 10 years after retirement (until 65) of those who retired at 55 , and for the first five years (until 65) for those who retired at 60 .

We identified subjects through Shell Oil's health surveillance system. ${ }^{7}$ This system was established in 1979 and contains data on vital status and other health related variables for all US employees of the company from 1973 onwards. We used several sources to determine the vital status of the subjects as of 31 December 2003. We supplemented the company records with results of a data linkage search with the National Death Index, which has been shown to ascertain $97 \%$ of deaths since $1979 .{ }^{89}$ Additionally, we carried out a data linkage search between company records and the master beneficiary record file of the Social Security Administration to identify any deaths that may have been missed by the National Death Index. We assumed subjects to be alive if they were not identified by the above sources. Details of this process have been reported elsewhere. ${ }^{10}$

The outcome variables for the survival analysis were time to death or end of the study, and the censoring variable (dead or living). Covariates in the analysis included categorical variables representing sex and employment grade, and a continuous vari- 
Table 1 Characteristics of employees of Shell Oil, United States, from 1 January 1973 to 31 December 2003. Values are numbers (percentages) unless stated otherwise

\begin{tabular}{|c|c|c|c|c|c|}
\hline Characteristic & Men & Women & High socioeconomic status* & Low socioeconomic status $\dagger$ & Total No \\
\hline Retired at 55: & $1276(89)$ & $163(11)$ & $731(51)$ & $708(49)$ & 1439 \\
\hline Reached 65 during study period & $754(90)$ & $85(10)$ & $475(57)$ & $364(43)$ & $839 \ddagger$ \\
\hline Retired at 60: & $1919(91)$ & $197(9)$ & $1041(49)$ & $1075(51)$ & 2116 \\
\hline Reached 65 during study period & $1765(91)$ & $164(9)$ & $1022(53)$ & 907 (47) & $1929 \S$ \\
\hline Retired at 65 & $788(88)$ & $112(12)$ & $396(44)$ & $504(56)$ & 900 \\
\hline Working at 55 & $13611(88)$ & $1932(12)$ & $7329(47)$ & 8214 (53) & 15543 \\
\hline Working at 60 & $5788(85)$ & $995(15)$ & $2703(40)$ & $4080(60)$ & 6783 \\
\hline
\end{tabular}

*Managerial or professional positions.

tSkilled, semiskilled, non-skilled, or clerical positions.

† 600 employees excluded from subgroup, 137 died and 463 were censored because they did not reach 65 during study period.

$\S 0 f 187$ employees excluded from subgroup, 98 died and 89 were censored because they did not reach 65 during study period.

able representing the calendar year that the subjects entered the study. Adjustment for year of entry to the study controlled for the effect of changes in mortality trends over the study period. We used employment grade as a proxy for socioeconomic status, a high status being assigned for employees in managerial or professional positions and a low status being assigned for those in skilled, semiskilled, non-skilled, or clerical positions.

We used Kaplan-Meier survival curves to graphically present the unadjusted survival of subjects who retired early at 55 or 60 compared with those who retired at 65 . We used the log rank test for the equality of survivor functions to determine whether there was a significant difference $(\mathrm{P}<0.05)$ between the survival curves.

We used the Cox proportional hazards model to estimate the hazard ratios of death between the early and normal retirement groups, ${ }^{11}$ with adjustment for sex, calendar year of entry into the study, and socioeconomic group. The Wald $\chi^{2}$ test was used to test the significance of the hazard ratios. All statistical analyses were carried out using SAS version 8.2 and Stata version 8.0.

\section{Results}

Women accounted for about $11 \%$ (10\% among early retirees and $12 \%$ among those retiring at 65 ) of the study population during follow-up. More than half of early retirees who reached 65 (57\% who retired at 55 and $53 \%$ who retired at 60 ) were in the high socioeconomic group whereas less than half (44\%) of those who retired at 65 were in this group (table 1). The Kaplan-Meier survival curve shows a consistently lower probability of survival for employees who retired at 55 (173 deaths) than for those who retired at 65 (462 deaths; fig 1). This difference was not, however, statistically significant $(\mathrm{P}=0.09, \log$ rank test). Likewise, the risk of death was similar between these two retirement groups (unadjusted hazard ratio $1.17,95 \%$ confidence interval 0.98 to 1.41 ). For most of the follow-up period the survival curves were similar for employees who retired at 60 and those who retired at 65 (581 and 541 deaths). On the basis of a small number of deaths $(n=51)$, however, the probability of survival for the group who retired early at 60 was higher in the last eight years (after age 83; fig 2). The log rank test did not support a significant difference between the groups $(\mathrm{P}=0.20)$ and this early retirement group was not at increased risk of death (hazard ratio $0.92,0.82$ to 1.04 ).

After adjustment for sex, calendar year of entry to the study, and socioeconomic status, employees who retired at 55 and were still alive at 65 had significantly higher mortality than those who retired at 65 (hazard ratio $1.37,1.09$ to 1.73 ; table 2). The risk of dying was about $80 \%$ greater in men than it was in women $(1.83$, 1.34 to 2.48 ) and retirees in the low socioeconomic category had a higher mortality than retirees in the high category $(1.17,1.01$ to
1.36). Mortality was lower among more recent retirees $(0.98,0.97$ to 1.00$)$. Among employees who retired at 60 , mortality was similar to those who retired at 65 (hazard ratio $1.06,0.92$ to 1.22 ). Men had a higher mortality than women (1.48, 1.16 to 1.89), and mortality was lower among more recent retirees $(0.97,0.96$ to 0.99). Mortality did not, however, differ significantly by socioeconomic status (1.09, 0.97 to 1.23 ; table 2$)$.

Regardless of socioeconomic status, employees who retired at 55 had a higher risk of mortality than those who retired at 60 (table 3). Employees who retired at 55 in the high socioeconomic group had a $20 \%$ increase in risk of death (hazard ratio 1.21, 0.88 to 1.67), whereas employees who retired at 55 in the low socioeconomic group had nearly a $60 \%$ increase in risk (1.58, 1.15 to 2.18). We found no difference in mortality by socioeconomic status in the group that retired at 60 .

We could not assess directly the issue of whether employees who retired at a younger age were in poorer health than those who retired later as data were not available to identify the type of

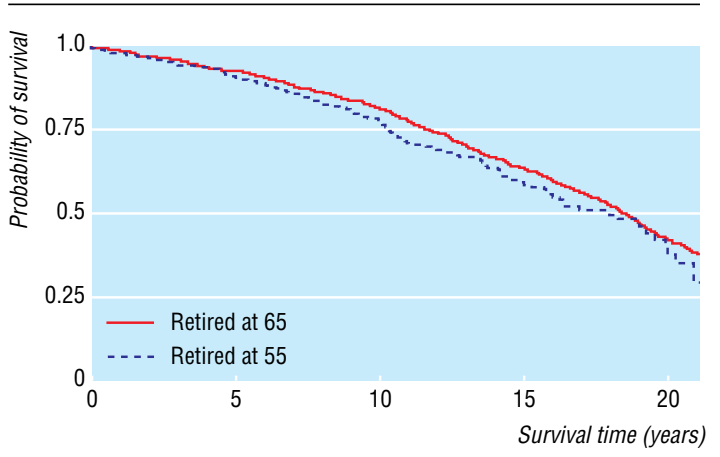

Fig 1 Kaplan-Meier survival curves for employees of Shell Oil, United States, who retired early at 55 and survived to 65 and those who retired at 65

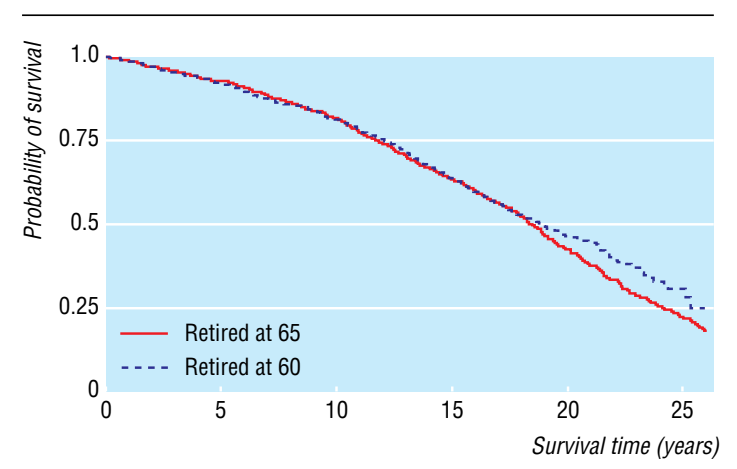

Fig 2 Kaplan-Meier survival curves for employees of Shell Oil, United States, who retired early at 60 and survived to 65 and those who retired at 65 
Table 2 Adjusted hazard ratios (95\% confidence intervals) by explanatory variables for employees of Shell Oil, United States, who retired early at 55 or 60 compared with those who retired at 65

\begin{tabular}{|c|c|c|}
\hline Explanatory variables & No of subjects & Adjusted hazard ratio* $(95 \% \mathrm{CI})$ \\
\hline \multicolumn{3}{|c|}{ Retired at 55 and reached 65 during study period $\dagger$} \\
\hline \multicolumn{3}{|l|}{ Retirement group: } \\
\hline Retired at 65 & 900 & 1.00 \\
\hline Retired at 55 & 839 & 1.37 (1.09 to 1.73$)$ \\
\hline \multicolumn{3}{|l|}{ Sex: } \\
\hline Women & 197 & 1.00 \\
\hline Men & 1542 & 1.83 (1.34 to 2.48$)$ \\
\hline \multicolumn{3}{|l|}{ Socioeconomic status: } \\
\hline High $\ddagger$ & 871 & 1.00 \\
\hline Low§ & 868 & 1.17 (1.01 to 1.36$)$ \\
\hline $\begin{array}{l}\text { Calendar year of entry to } \\
\text { study }\end{array}$ & 1739 & 0.98 (0.97 to 1.00$)$ \\
\hline \multicolumn{3}{|c|}{ Retired at 60 and reached 65 during study period $\dagger$} \\
\hline \multicolumn{3}{|l|}{ Retirement group: } \\
\hline Retired at 65 & 900 & 1.00 \\
\hline Retired at 60 & 1929 & 1.06 (0.92 to 1.22$)$ \\
\hline \multicolumn{3}{|l|}{ Sex: } \\
\hline Women & 276 & 1.00 \\
\hline Men & 2553 & 1.48 (1.16 to 1.89$)$ \\
\hline \multicolumn{3}{|l|}{ Socioeconomic status: } \\
\hline High $\ddagger$ & 1418 & 1.00 \\
\hline Low§ & 1411 & 1.09 (0.97 to 1.23$)$ \\
\hline $\begin{array}{l}\text { Calendar year of entry to } \\
\text { study }\end{array}$ & 2829 & 0.97 (0.96 to 0.99$)$ \\
\hline
\end{tabular}

*Hazard ratios reflect values with all other variables in model.

†1 January 1973 to 31 December 2003.

†Managerial or professional positions.

§Skilled, semiskilled, non-skilled, or clerical positions.

retirement for each employee (for example, retirement due to disability compared with normal retirement). If early retirement before 65 is taken by some workers because of failing health, however, mortality would be expected to be higher early in retirement. Table 4 shows the mortality for the first 10 years after retirement at 55 and for the first five years after retirement at 60 compared with employees who continued working at these ages. Regardless of socioeconomic status, employees who retired at 55 had almost a twofold higher mortality than those who continued working (1.89, 1.58 to 2.27). The mortality of employees who retired at 60 was similar to those who continued working at 60 (1.04, 0.82 to 1.31). Employees in the high socioeconomic group who retired at 60 , however, had a $20 \%$ lower mortality $(0.81,0.54$

Table 3 Adjusted hazard ratios (95\% confidence intervals) for early retirement by socioeconomic status

\begin{tabular}{|c|c|c|}
\hline Socioeconomic status & No of subjects & $\begin{array}{c}\text { Adjusted hazard ratio* }(95 \% \\
\text { CI) }\end{array}$ \\
\hline \multicolumn{3}{|l|}{ Hight: } \\
\hline Retired at 65 & 396 & 1.00 \\
\hline $\begin{array}{l}\text { Retired at } 55 \text { and reached } 65 \\
\text { during study periodf }\end{array}$ & 475 & 1.21 (0.88 to 1.67 ) \\
\hline $\begin{array}{l}\text { Retired at } 60 \text { and reached } 65 \\
\text { during study period } \neq\end{array}$ & 1022 & 1.13 (0.92 to 1.38 ) \\
\hline \multicolumn{3}{|l|}{ Low§: } \\
\hline Retired at 65 & 504 & 1.00 \\
\hline $\begin{array}{l}\text { Retired at } 55 \text { and reached } 65 \\
\text { during study periodf }\end{array}$ & 364 & 1.58 (1.15 to 2.18 ) \\
\hline $\begin{array}{l}\text { Retired at } 60 \text { and reached } 65 \\
\text { during study periodf }\end{array}$ & 907 & 1.00 (0.82 to 1.21$)$ \\
\hline
\end{tabular}

Table 4 Adjusted hazard ratios (95\% confidence intervals) for first 10 years after retirement at 55 and for first five years after retirement at 60

\begin{tabular}{lcc} 
Socioeconomic status & No of subjects & Adjusted hazard ratio* $\mathbf{( 9 5 \%} \mathbf{~ C l})$ \\
\hline Hight: & & \\
\hline Working at 55 & 7329 & 1.00 \\
\hline Retired at 55 & 731 & $1.98(1.49$ to 2.62$)$ \\
\hline Working at 60 & 2703 & 1.00 \\
\hline Retired at 60 & 1041 & $(0.54$ to 1.20$)$ \\
\hline Lowł: & & 1.00 \\
\hline Working at 55 & 8214 & $1.84(1.45$ to 2.35$)$ \\
\hline Retired at 55 & 708 & 1.00 \\
\hline Working at 60 & 4080 & $1.21(0.91$ to 1.61$)$ \\
\hline Retired at 60 & 1075 & 1.00 \\
\hline Total: & & $1.89(1.58$ to 2.27$)$ \\
\hline Working at 55 & 15543 & 1.00 \\
\hline Retired at 55 & 1439 & $1.04(0.82$ to 1.31$)$ \\
\hline Working at 60 & 6783 &
\end{tabular}

${ }^{*}$ Adjusted for sex and calendar year of entry to study.

†Managerial or professional positions.

‡Skilled, semiskilled, non-skilled, or clerical positions.

to 1.20 ), whereas employees in the low socioeconomic group had a $20 \%$ increased mortality $(1.21,0.91$ to 1.61$)$.

\section{Discussion}

The long term survival of people who retire early at ages 55 or 60 is no better than that of those who retire at 65 , especially for those who retire at 55 . On the contrary, mortality improved with increasing age at retirement for people from both high and low socioeconomic groups, defined according to employment grade. It is reasonable to assume that some workers retired at 55 because of failing health, as the mortality for this group in the first 10 years after retirement was almost twofold higher than that of their peers who continued working. The health status of those who retired at 60 , however, was similar to those who continued working at 60 . It is interesting to note that mortality among those who retired at 60 in the high socioeconomic group was lower than that of their working peers whereas it was higher for the low socioeconomic group, although the differences were not statistically significant. In addition, more than half of early retirees were in the high socioeconomic group compared with only $44 \%$ of those who retired at 65 . Similar observations have been reported..$^{12} 13$

The finding of lower survival among employees of low socioeconomic status, regardless of age at retirement, is not unexpected and is consistent with other studies. ${ }^{14-17}$ Similarly, it was not unexpected that men had statistically higher mortality than women and that those retiring in more recent years had better survival.

Several studies found lower survival among those retiring early and attributed this to poor health status forcing early retirement. ${ }^{13}$ Our study confirmed the finding of lower survival in people who take early retirement at age 55 , but we did not find evidence of lower survival among those who retired at 60 . To reduce potential bias due to differences in health status between early and late (age 65) retirees, we excluded survival for the first 10 years of follow-up after retirement at 55 and for the first five years after retirement at 60 for early retirees. Although the effect of early retirement because of failing health may not be totally eliminated, survival rates remained significantly greater for those who retired at 65 compared with those who retired at 55 . The difference in survival between those who retired between 60 and 65 was, however, small and not statistically significant. 


\section{What is already known on this topic}

There is a widespread perception that early retirement is associated with longer life expectancy and later retirement is associated with early death

No consensus has been reached on the comparative survival or mortality of people who retire early or late

\section{What this study adds}

Early retirement at 55 or 60 is not associated with increased survival

Employees who retired at 60 had similar survival to those who retired at 65

Differences in mortality could not be attributed to the effects of employee's sex, year of entry to the study, or socioeconomic status

In summary, employees who retired at 55 had a significantly increased mortality compared with those who retired at 65 . This difference could not be attributed to the effects of sex, socioeconomic status or calendar year of entry to the study, although poorer health status of some early retirees may play some part. Survival for employees who retired at 60 was similar to that of employees who retired at 65 . Retiring at 65 was not associated with a greater risk of mortality than retiring at 55 or 60 in a cohort of Shell Oil employees.

Contributors: SPT, RPD, and GJ developed the aim and scope of the study. SPT, JKW, and FSA carried out the statistical analysis. All authors contributed to the interpretations and to the final manuscript. SPT is the guarantor

Funding: None.

Competing interests: None declared.

Ethical approval: Not required.
Haynes SG, McMichael AJ, Tyroler HA. Survival after early and normal retirement. J Gerontol 1978;33:269-78.

2 Ekerdt DJ, Baden R, Bosse R, Dibbs E. The effect of retirement on physical health. Am J Public Health 1983;73:779-83.

3 Morris JK, Cook DG, Shaper AG. Loss of employment and mortality. BMJ 1994;308:1135-9.

4 Trichopoulos D. Any questions? BMJ 1996;312:632.

5 Padfield A. Myths in medicine. BMJ 1996:312:1611.

Lin S. Optimum strategies for creativity and longevity. 2002. http://www.geocitiescom dtmcbride/health/retirement age.html (accessed 16 Feb 2005).

7 Joyner RE, Pack PH. The Shell Oil Company's computerized health surveillance system. J Occup Med 1982;24: 812-4.

8 Cowper DC, Kubal JD, Maynard C, Hynes DM. A primer and comparative review of major US mortality databases. Ann Epidemiol 2002;12:462-8.

9 Acquavella JF, Donaleski D, Hanis NM. An analysis of mortality follow-up through the national death index for a cohort of refinery and petrochemical workers. Am J Ind Med 1986;9:181-7.

10 Tsai SP, Wendt JK, Cardarelli KM, Fraser AE. A mortality and morbidity study of refinery and petrochemical employees in Louisiana. Occup Environ Med 2003;60:627-33.

11 Cox DR. Regression models and life tables (with discussion). J R Stat Soc 1972;34:187220.

12 Mein G, Martikainen P, Hemingway H, Stansfeld S, Marmot M. Is retirement good or bad for mental and physical health functioning? Whitehall II longitudinal study of civil servants. J Epidemiol Community Health 2003;57:46-9.

13 Mein G, Martikainen P, Stansfeld SA, Brunner EJ, Fuhrer R, Marmot MG. Predictors of early retirement in British civil servants. Age Ageing 2000;29:529-36.

14 Lantz PM, House JS, Lepkowski JM, Williams DR, Mero RP, Chen J. Socioeconomic factors, health behaviors, and mortality: results from a nationally representative prospective study of US adults. JAMA 1998;279:1703-8.

15 Chandola T. Social class differences in mortality using the new UK national statistics socio-economic classification. Soc Sci Med 2000;50:641-9.

16 Mackenbach JP, Bos V, Andersen O, Cardano M, Costa G, Harding S, et al. Widening socioeconomic inequalities in mortality in six Western European countries. Int J Epidemiol 2003:32:830-7.

17 Muntaner C, Hadden WC, Kravets N. Social class, race/ethnicity and all-cause mortality in the US: longitudinal results from the 1986-1994 national health interview survey. Eur J Epidemiol 2004;19:777-84

(Accepted 16 August 2005)

doi 10.1136/bmj.38586.448704.E0

Shell Health Services, Shell Oil Company, 910 Louisiana, Houston, TX 77002,

USA

Shan P Tsai manager, epidemiology

Judy K Wendt senior epidemiologist

Robin P Donnelly director, health services

Farah S Ahmed epidemiology research associate

Shell International, Hague, Netherlands

Geert de Jong senior health adviser

Correspondence to: S P Tsai shan.tsai@shell.com 